\title{
Evaluation of Methidds to Estimate the Surface Downwelling Longwave Flux during Arctic Winter
}

\author{
MARC ChIACCHIO \\ Analyticul Servicess \& Materials, Inc. Hampton. Virginia \\ JFNNIFER FRANCIS \\ Instifute of Marine and Comstul Siciences. Rutgers University. New Brunswick. New Jerie's \\ Paul Stackhouse Jr. \\ NASA I.angley Researdh Center. Hamprom. Virginis
}

(Manuscript reccived 21 March 200)1. in tinal form 8 August 2001)

\begin{abstract}
Surface longwave radiation fuxes dominate the energy budget of nighttime polar regions, yet little is known about the relative ac curacy of existing satellite-based techniques to estimate this parameter. We compare eight methods to estimate the downwelling longwave radiation flux and to validate their performance with measure ments from two fiekl programs in the Arctic: the Coordinated Eastern Arctic Experiment (CEAREX) conducted in the Barents Sea curing the autumin and winter of 1988. and the Lead Experiment performed in the Beauliort Sea in the spring of 1992 . Five of the cight methods were developed for satellite-derived quantities. and three are simple paramets rizations bascd on surface observations. All of the algorithms require information about cloud fraction, which is provided from the NASA-NOAA Television and Infrared Observation Satellite (TIROS Operational Vertical Si)under (TOVS) polar pathtinder datasel (Path-P); some techniques ingest temperature and moisture profiles (al io from Path-P): une-half of the methods assume that clouds are opaque and have a constant geometric thickness of $50 \mathrm{hPa}$, and three include no thickness information whatsoever. With a somewhat linited validation dataset. i e following primary conclusions result: 1 ) all methods exhibit approximately the sitme correlations with $\mathrm{mt}$ asurements and $\mathrm{rms}$ differences, but the biases range from $-34 \mathrm{~W} \mathrm{~m}:(16 \%$ of the mean) to nearly $0: 2)$ the , rror analysis described here indicates that the assumption of a 50 -hPa cloud thickness is Ioo thin by a factor if 2 on average in polat nighttime conditions: 3) cloud-overlap techniques. which effectively increase mean cloul thickness, signilicantly improve the results: t) simple Arctic-specific parametcrization. pertormed poorly, frobably because they were developed with surface-observed cloud fractions whereas the tests discussed here used satellite-derived effective cloud fractions; and 5) the single algorithm that includes an evimate al cloud th chness exhibits the smallest differences from observations.
\end{abstract}

\section{Introduction}

In this investigation we : $x$ tend the work of Key et al. (1996) and evaluate the ability of several existing methods to estimate the surface downwelling flux of longwave radiation (DLF) (iver snow-and ice-covered surfaces, particularly at night. The algorithms examined by Key et al. (1996) are a l simple parameterizations empirically derived from st rface measurcments in the Arctic; here we also evalu te several techniques that ingest retrievals from satell te data. Our goal is to determine which method(s) should be used in computing DLF from satellite retricva $s$ for a varicty of applica-

Correspondung author address: Dr. Jenniter lirancis, Insitule ut Marine and Coastal Sciences, Rulgers University, 71 Dulley Ro., New Brunswick. NJ $08901-8521$.

E-mail: francis (a) imcs, rutgers.sdu tions, including a long-term dataset for studies of variability and change and use as forcing tields for modeling studies. We also extend the work of Key et al. (1997) in evaluating the sensitivity of DLF to perturbations in various atmospheric parameters with the intent of identifying variables that require improved retrieval accuracy.

Polar regions are notoriously problematic for global surface radiation budget (SRB) algorithms based on satellite data. because several factors complicale the retrieval process and few validation data are available. Because the high latitudes are recognized as climatically sensitive areas, there is a strong demand from the scientific community for reliable, long-term surface radiation datasets for the polar regions. We employ a combination of satellite retrievals from the National Aeronautics and Space Administration (NASA)-National 
-

$Y$ 
Oceanographic and Atmosp teric Administration (NOAA) Television and Infrare 1 Observation Satellite Operational Vertical Sounder (7OVS) polar pathfinder (hereinafter, Path-P) dataset (F rancis and Schwciger $2000)$ with surface observations from radiometers, ceilometers, and surface observers to evaluate the performance of several existing algorithins to estimate surface longwave fluxes in the Arctic.

Longwave radiation dominate; the Arctic surface energy budget for almost one-half of the year when insolation is absent or weak. During the polar winter, turbulent fluxes are small in sca-jwe-covered regions, except over cracks in the ice when vertical air-ocean temperature and moisture gradients are large. In contrast to lower latitudes, at which low-les el temperature and water vapor content largely govern the DLF, clouds play the most important role in po:ar regions. Sensitivity studies by Key et al. (1997). Fiouin et al. (1988), and Chiacchio (2001) show that DI,F is most sensitive to cloud fraction, cloud thickness (or liquid water path). and cloud-base height. Of these rarameters, parsive satellite sensors can be used to estir late only cloud fraction and cloud-top height during polar night conditions. and even these have much larger uncertainties than do estimates from other parts of the globe. Algorithms to detect clouds and to diagnose their properties often fail over snow- and ice-covered areas because of frequent surface-based temperature inver ;ions that confound satellite cloud-detection algorithm; and introduce uncertainty into satellite-retrieved tempcrature profiles. Shortwave channels, especially new sensors that measure radiances in the $1.6-\mu \mathrm{m}$ wavelenrth region, add considerable information, but historicia visible data are limited by the lack of contrast between clouds and snow. Efforts are underway to infer polar cloul characteristics beyond fraction and cloud-top height, l-ut they are still experimental.

Several algorithms and paramiterizations exist for estimating DLF from satellite-derived information, but intercomparisons and validation for polar-night conditions have not been performed. The shjective of this investigation is to compare DLF values computed with eight different methods quantitatively. to validate results with measurements from surface-bas ad instruments and human observers. to identify probibble causes for errors in each method, and to make reconmendations as to which algorithm(s) provides the best estimates of IDLF in the Arctic night.

\section{Data sources and tools}

a. Satellite-derived products

Several of the methods und $r$ investigation require temperature profiles. humidity profiles, surface temperature, cloud fraction. and/or cloud height. For this study, atmospheric state information is obtained from the NASA-NOAA TOVS Path-P dataset (Francis and
Schweiger 2000). The TOVS instrument, which has flown on NOAA polar-orbiting sensors since 1978. comprises the High-Resolution Infrared Radiation Sounder (HIRS), the Microwave Sounding Unit (MSU), and the Stratospheric Sounding Unit (SSU). Data from SSU are not used to create the Path-P dataset. HIRS measures radiances in 20 channels from the visible to infrared wavelengths with a resolution of $17 \mathrm{~km}$ at nadir, and MSU has four channels in the oxygen absorption band near $50 \mathrm{GH}$. The Path-P dataset was produced using the improved initialization inversion (31) processing algorithm for TOVS radiances, developed by the Aimospheric Radiation Analysis Group at the Laboratoire de Méléorologie Dynamique in Palaiseau. France (Chédin et al. 1985). The 3I algorithm was modified to improve retrieval accuracy over sea ice and snow [Francis (1994): Scott et al. (1999)]. Path-P products are provided daily on a $(100 \mathrm{~km})^{2}$ grid and include temperature and moisture profiles, surface skin temperature, cloud fraction and height. and a variety of other parameters. The 31 algorithm has at its core a comprehensive library of global atmospheric profiles $(-1800)$ that provides the first guess to this physical-statistical technique and consequently is able to capture the strong surface-based and elevated temperature inversions that are nearly ubiquitous in all seasons hut summer in the Arctic region. Validation of surface and $900-\mathrm{hPa}$ temperatures with radiosonde data reveals small mean errors (1.4 and 2.5 K). Retrieved inversion strength, however, is often less than radiosonde values owing to the coarse vertical resolution of the temperature profile, and the cap may be misplaced in the vertical by a few tens of hectopascals. The cloud fraction variable (labeled FCLD in the Path$P$ dataset) is an effective cloud fraction $A, \varepsilon$, which is the product of the fraction $A$, of the sky covered by cloud and the cloud emissivity $\varepsilon$. Cloud emissivity ranges between 0 an 1: therefore $A, \varepsilon$ is always less than or equal to $A_{\text {. }}$, which is the quantity reported by human observers. This distinction is significant in polar regions because optically thin clouds-even in the infraredare common, especially in winter. Hereinafter we abbreviate effective cloud fraction as $A_{a}$. and "cloud fraction" denotes the fraction of the sky covered by cloud $\left(A_{1}\right)$. See Schweiger et al. (2001) for additional information and validation results for the Path-P data.

\section{b. Validation datasets}

A significant problem in studying cloud or surface characteristics in this region is the paucity of measurements, especially in winter when DLF is the dominant component of the surface energy budget. Observations from two field experiments are used in this study. The first is the drift phase of the Coordinated Eastern Arctic Experiment (CEAREX: CEAREX Drift Group 1990), which was conducted in the eastern Arctic Basin from September of 1988 through January of 1989 (Fig. 1). The experiment included two research vessels and an 


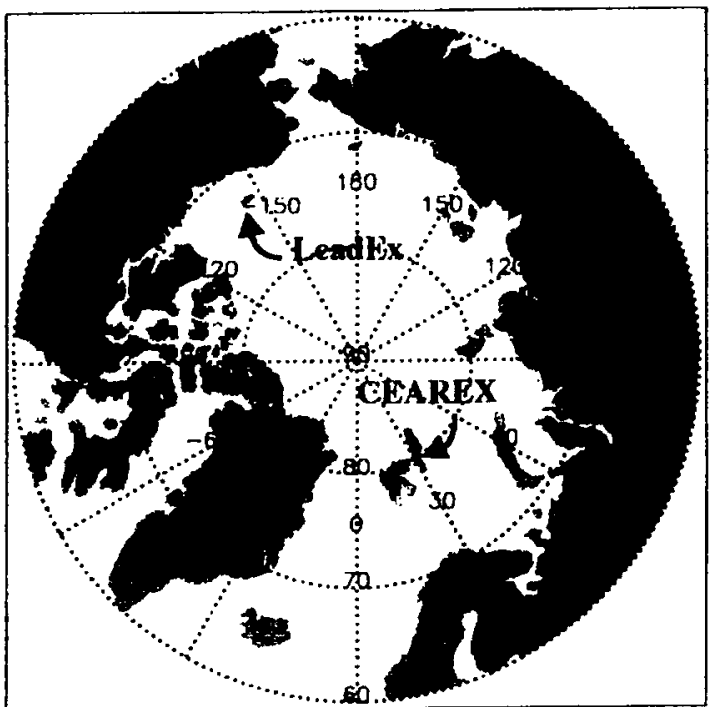

Fici. 1. Lexations of leadEx and (t.AREX measurement sites.

array of surface camps at which a variety of meteorological and oceanographic measurements were made. In this study we use data obtained aboard the R/V $P_{0}$ larbjörn, which include downward infrared fluxes (be(ween 4 and $50 \mu \mathrm{m}$ ) from an Eppley Laboratory. Inc., pyrgeometer, which has a nominal instrument error of $5 \mathrm{~W} \mathrm{~m}$ - (CEAREX Drift Group 1990). Owing to the lack of solar radiation during CEAREX, as well as the low sun angles and large cloud fractions during the 1992 Beaufort Sea I.ead Experiment (LeadEx). we assume errors in radiometer measurements resulting from solar contamination are small. The radiometer domes required cleaning hourly to remove frost and precipitation; only measurements following a cleaning were used to compute daily-average flux values, which we compare with daily-average satellite-derived DLFs. The differing space scales of Path-P data and surface point measurements is a possihlc source of error. Schweiger et al. (2001) analyzed correlations between timc-averaged point measurements of cloud fraction and spatially averaged satellite values and found that correlations were low for timescales shorter than 2 days and peak at 8 days. Becautse clouds are the dominant factor in determining DLF in the Artic winter, we assume these correlations also apply to DLF. They speculate that the lack of strong correlation at short timescales may be caused by the differing perspectives of satellite versus surface observations (view from above or below). Another probable cause is that smaller variations occur at short timescales, which may cause this signal to be lost in noise, whereas large variations may nccur at long timescales and so are more detectable above the noise.

Data from LeadEx (LeadEx Group 1993) are also used to validate DL.F computed from each of the eight algorithms. This tield program was conducted in the Beaufort Seat at a camp on the pack ice that dritted westward from 24 March 1992 until 25 April 1992 (Fig. 1). The main objectives of the experiment were to study the cracklike openings (leads) in sea ice formed by the ice deformation and to understand the effects of leads on the polar ocean and atmosphere. In addition to radiation measurements, we use cloud-base height retrievals from a lidar ceilometer to compare with Path-Pderived values. The vertical resolution of the ceilometer retrievals was $30 \mathrm{~m}$, and the instrument could observe cloud bases up to $8 \mathrm{~km}$. These ceilometer estimates are not considered to be reliable for absolute validation. however, owing to reported problems in detecting thin. low-level, ice clouds (O. Persson 1999, personal communication). Thirty-second ceilometer values are averaged over $24 \mathrm{~h}$ to be consistent with Path-P products.

\section{¿. Radiative transfer model}

Sensitivity tests and calculations of surface fluxes are performed using a forward radiative transfer model called Streamer, which was assembled by J. Key and A. Schweiger (Key and Schweiger 1998). Streamer is a publicly available, highly flexible package that can be used to calculate shortwave and longwave radiances and fluxes for a wide variety of atmospheric and surface conditions. Absorption and scattering by gases is parameterized for 24 shortwave and 105 longwave bands. Built-in data include water and ice cloud optical properties, aerosol profiles, and seven standard-atmosphere profiles, or users can provide their own. Each scene can include up to 10 cloud types, up to 10 overlapping cloud sets of up to 10 clouds each, and up to three surface types. Also, spectral albedos for various surface conditions are included. The number of streams used in the calculation can be varied; two are used in this study. Modeled fluxes for standard atmospheres were compared with calculations by approximately 37 other models presented in the report of the Intercomparison of Radiation Codes in Climate Models project (Ellingson et al. 1991). Streamer-computed fluxes were within $5 \%$ (1 standard deviation) of the mean of all models (Francis 1997).

\section{Sensitivity of DLF to atmospheric parameters}

Sensitivity studies are performed to determine the likely errors in DLF resulting from uncertainty in cloud parameters and from published uncertainties in Path-P products. DLF is calculated using Streamer for typical winter and summer Arctic conditions and with expected rms errors (in parentheses) for each of the following slate variables under clear conditions: surface skin temperature $( \pm 3 \mathrm{~K})$. lemperature profile $( \pm 3 \mathrm{~K}$ at all levels). and moisture profile ( $\pm 30 \%$ at all levels). In addition. we estimate the sensitivity of DLF to varying hulk cloud properties: fraction, thickness, base height. liquid water content (LWC), and effective droplet radius $r$. Each calculation includes orone amounts for a stan- 

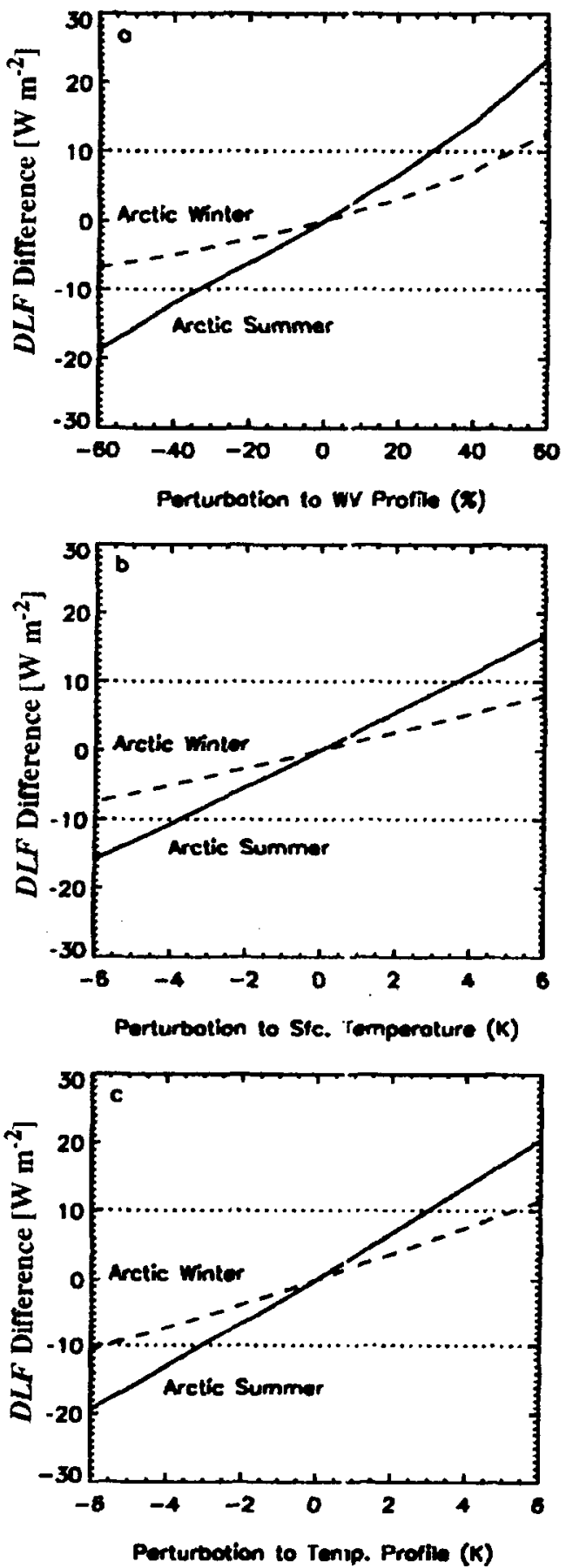

Fic. 2. Sensitivity of DLF to perturhations in the fal water vapor protile $\left(3()_{*}^{\prime}\right)$. (b) surfice temperalture $3 \mathrm{KI}$. and (c) (c)mplerature protile $1.3 \mathrm{~K}$ ) for standard Arctic sums ter (solid line) and winter (dashed) conditions. Dotled lines indicilte $10 \mathrm{~W}$ m : error hounds.
TAB! I. 1. Resull, from sensitivily tests

\begin{tabular}{|c|c|c|}
\hline $\begin{array}{l}\text { Viriable name } \\
\text { rexpected rms crror in } \\
\text { Path-P retricsult }\end{array}$ & $\begin{array}{l}\text { DLF errur } \\
\left.\text { (W } 1)^{\prime}\right)\end{array}$ & $\begin{array}{l}\text { DI.F Error } \\
1 \mathrm{~W} \text { m }\end{array}$ \\
\hline Surtace skin temperature $(3 \mathrm{KJ}$ & I iwinter & 8 (stummer) \\
\hline Temperallurc prodile $(3 \mathrm{~K})$ & S (winter) & I0) (summer) \\
\hline Water valpor prodile $(30 \%)$ & $\$ .5$ (winter) & I0 (stummer) \\
\hline Cloud friction $(30 \%)$ & 14 llow cloud) & 8 (high cloud) \\
\hline
\end{tabular}

dard subarctic winter profile, and the carbon dioxide concentration is fixed at 350 ppmv. Clouds in these tests are composed of spherical water droplets with a nominal cloud thickness of $50 \mathrm{hPa}$, an $\mathrm{LWC}$ of $0.20 \mathrm{~g} \mathrm{~m}$ '. and a typical $r$, of $8 \mu \mathrm{m}$ (Curry and Ehert 1992). We teel justified in considering only water clouds, because liquid water was detected in over one-half of the clouds during the Surface Heat Budget of the Arctic (SHEBA) experiment in every month except December (Intrieri et al. 2001, and hecause phase alone has a negligible effect on DLF (Francis 1999).

Results of sensitivity lests for temperatures and water vapor are shown in Fig. 2 and are summarized in Table 1. These results are consistent with those of Key et al. (1997) and show that errors in DLF arising from documented uncertainties in satellite-derived temperature and moisture profiles will be well within the $10 \mathrm{~W} \mathrm{~m}$ : threshold that has heen suggested by the World Climate Rescarch Programme (WCRP) as the target accuracy for surface flux estimates (Raschke et al. 1990). We also use Streamer to test the sensitivity of DLF 10 uncertainties in TOVS-retrieved surface-based inversions. We calculate DLF for a typical winter surface-based inversion (1.3 K difference between the surface and top of the inversion at $900 \mathrm{hPa}$ ) and for a temperature profile with the inversion smeared out and a positive lapse rate throughout. A typical 50-hPa-thick water cloud is placed with its top at $900 \mathrm{hPa}$ (top of the inversion). The difference in DLF holween these two model runs is less than $3 \mathrm{~W} m$ 2 (inversion run is smaller). Because this scenario is likely a worst case. we conclude that any errors in TOVS-retrieved inversion strength, height. or even existence would not result in the magnitude of DLF deficiencies we observe in many of the algorithms.

Figure 3 shows the computed sensitivity of DLF to cloud fraction and geometric thickness. A $30 \%$ error in low-cloud fraction would result in DLF errors in excess of the WCRP threshold. but DLF is less sensitive to uncertaintics in high-cloud fractions. DLF is highly sensitive to cloud thickness-more so for low clouds: an error of $10 \mathrm{~W} \mathrm{~m}$ : could arise from assuming a cloud is only $20 \mathrm{hPa}$ thicker than its actual value. This is an important point in our later discussion of the assumption in some algorithns that clouds are a constant $50 \mathrm{hPa}$ thick.

Figure 4 shows the sensitivity of DLF to cloud LWC for varying droplet effective radii and cloud-base heights, with and without a surface-hased temperature 

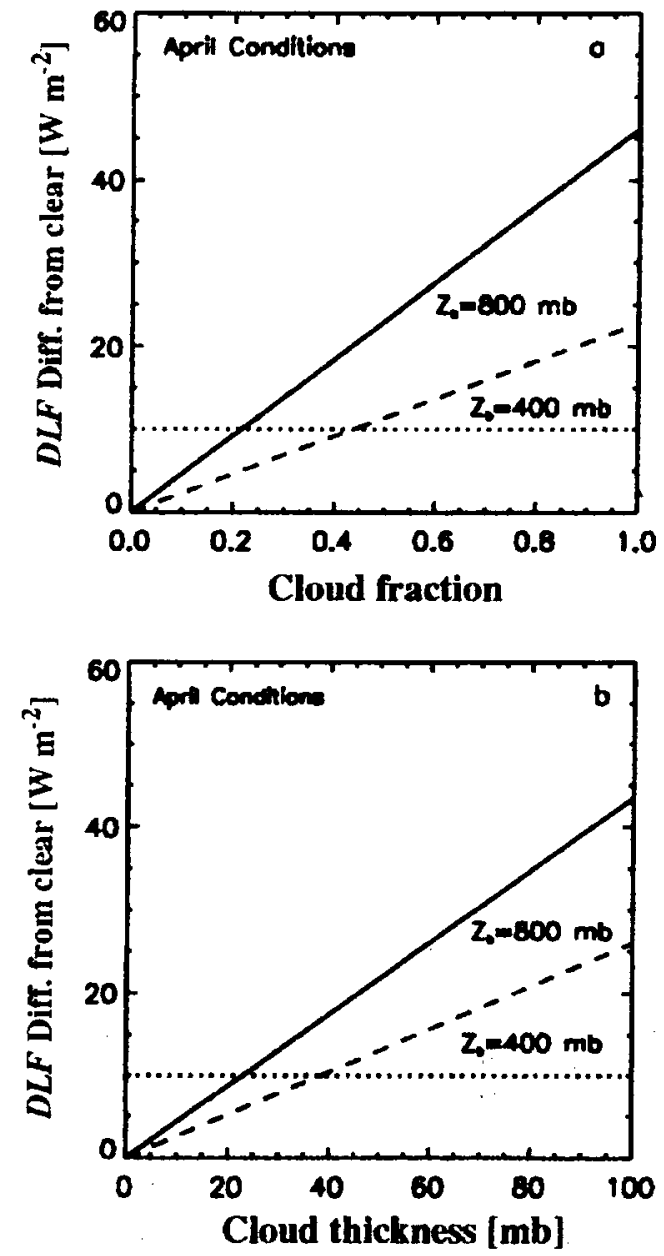

Fici. 3. Sensituvity of DLF to perturbations in (a) cloud fraction and (b) cloud thickness. with cloud-base hejghts at $8\left(K^{\prime}\right)$ and $4(0) \mathrm{hPa}$ in typical Apr conditions in the central Arctic. Cluuds are composed of spherical water droplets with a nominal cloud thickness of $50 \mathrm{hPa}$. an $L W\left(W^{\circ}\right.$ of $0.20 \mathrm{~g} \mathrm{~m}$ : and a typical equivalent radius $r_{\text {, of }} 8 \mu \mathrm{m}$.

inversion. We use temperature and water vapor profiles typical for April, and LWC is varied from 0.0 to $0.2 \mathrm{~g}$ $m$ ". In each of these experiments, it is apparent that the DLF is extremely sensitive to the LWC in thin, high clouds that contain less than $0.02 \mathrm{~g} \mathrm{~m}$ ' of water and in low clouds with less than $0.05 \mathrm{~g} \mathrm{~m}^{3}$. For thicker clouds. DLF is no longer sensitive to LWC: that is, the cloud is optically thick in the infrared. Cloud droplet effective radius in this size range, however, has a negligible effect on DLF. This result is consistent with results by Francis (1999) that show little sensitivity of infrared cloud radiative forcing by water clouds $\left(r_{r}=\right.$ $10 \mu \mathrm{m})$ versus ice clouds $\left(r_{r}=50 \mu \mathrm{m}\right)$. Figure $4 \mathrm{~b}$ shows that DLF is more sensitive to the LWC of low clouds than of high clouds and thal. for optically thick clouds, in error of $10 \mathrm{~W} \mathrm{~m}^{-2}$ would result from an error in cloud-hase height of approximately $150 \mathrm{hPa}$. Figure $4 \mathrm{c}$ illustrates the effect of a cloud base lying above and
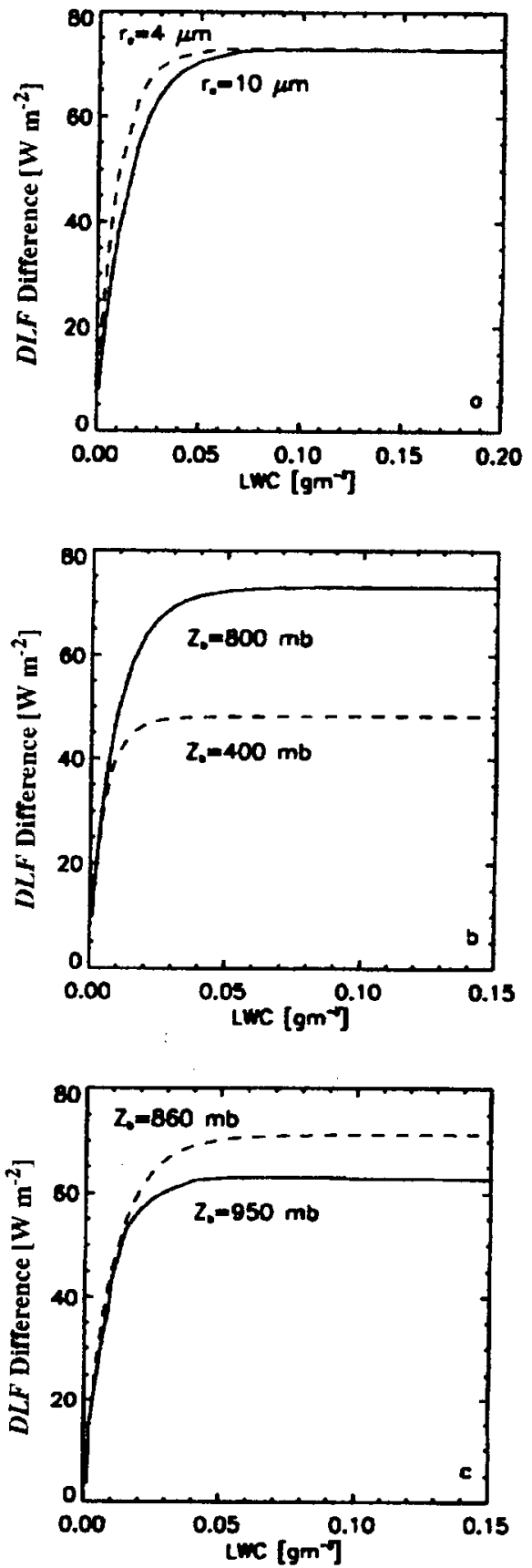

FI(j. 4. Sensitivity of DLF to perturbations in LWC with (a) $r=$ 4 and $10 \mu \mathrm{m}$, (b) cloud-base heights at 400 and $800 \mathrm{hPa}$ with no temperature inversion. and (c) cloud-base heights at 860 and $950 \mathrm{hPa}$ with a temperalure inversion. Ordinate is cloudy minus clear DI,F.

below the cap of a surface-based temperature inversion. The results of these sensitivity tests for bulk cloud parameters are also generally consistent with those of Key et al. (1997), atthough we test some different variables and, in some cases, over a more widely varying range of values. We are interested only in the sensitivity of 
I 131 1. 2. Summary af iuputs and asumplion for DI.t algurillums.

\begin{tabular}{|c|c|c|}
\hline Algorithm relerence & Required Input data* & Assumption: \\
\hline Francis $(1007)$ & $\pi, 3, q 1=\ldots, r$, TB八. $\%$ & One ciond layer \\
\hline Frouin et al. (1988). FI with (werlat) & $T(z), 4(z), A r$ & Owerlappint cloud layers. $Z=50 \mathrm{hPa}, \varepsilon-1 . T_{1}=1<0$ \\
\hline Frouin et al. $(1988) .12$ & $M(-) .(1:) . A$ & One clond layer, $7=50 \mathrm{hPa}, \mathrm{e}=1.7(5) \therefore 0$ \\
\hline Matrshumeva $(1966)$ & A. 7. & - \\
\hline Maykiu itnd Clumsch (1973) & A. $T$ & 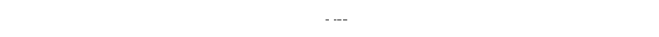 \\
\hline Gupta $(1989\}$ & $T_{1}=\varphi_{1}=$ ) A P. $T$. & Ont cloud layer. $7 .=50 \mathrm{hPa} .8:=1 . \%(=)<0$ \\
\hline Zillman (1972) & A $T$ & - \\
\hline Frouin el al. $1198 \times 1, \mathrm{Fl}$ & 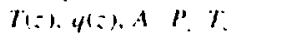 & One cloud layer. $7,-50 \mathrm{hPa}, \varepsilon=1, T(z)=0$ \\
\hline
\end{tabular}

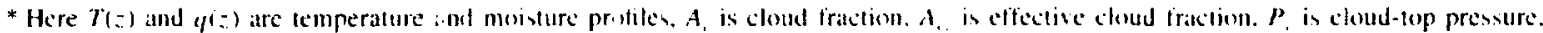

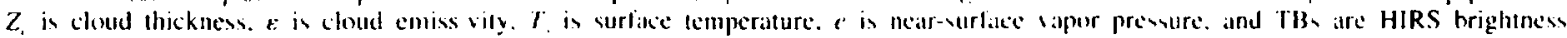
temperatures.

DLF to individual variables, given that part of our goal is to identify which satellite-relrieved quantities lack sufficient accuracy for DLF calcu ations. For an analysis of the overall uncertainty in DI.F see Key et al. (1997).

From the results of these tests, we conclude that DLF is most sensitive to errors in clou 1 fraction and to LWC in thin clouds and that DLF is relatively insensitive to droplet size. Known uncertaintics in satellite-retrieved temperature and water vapor profiles result in DLF errors within $10 \mathrm{~W}$ m : For further details on sensitivity tests, see Chiacchio (20)1).

\section{Methodology}

We evaluate the ability of sever al methods to estimate DLF by comparing daily-meall-s alculated values from a $(100 \mathrm{~km})^{2}$ grid box to surlace-measured DLF from two field experiments in the Arctic. Some of the algorithms, such as those of Gupla (1989) and Frouin ct al. (1988), are being used globally, and we compare their performance with Arctic-specifi: algorithms, such as that of Francis (1997). We also evaluate three simple empirical parameterizations devoloped for Arctic conditions: Marshunova (1966), Zill nan (1972). and Maykut and Church (1973). These parameterizations are among the longwave flux methods examined by Key et al. (1996). yet we do not consicler the Schmetz et al. (1986) method, because it wiss developed for daylight conditions. In this section we desaribe each method and the required input data. A summary of the assumptions and required information for wath method is given in Table 2.

\section{a. Gupta (1989)}

This algorithm was used to generate a global 8-yr SRB datasel (Gupta et al. 1999, and also is included among other algorithms in hoth the Clouds and the Earth's Radiant Energy System (CERES) and the WCRP-Global Energy and Waer Cycle Experiment (GEWEX) SRB projects. This rethod requires inputs for water vapor and temperature profiles, cloud fraction. and cloud-top pressure. which (juptil (1989) obtained from NOAA operational TOVS retrievals. and the
GEWEX SRB and CERES projects obtained from reanalysis dalasets (either the European Centre for Medium-Range Weather Forecasts or NASA: Data Assimilation Office). In this study, we instead use the Path-P products. because they are believed to be more accurate in Arctic condilions (Francis 1994). The primary assumptions of the Gupta ( 1989) lechnique are that clouds exist in a single. 5()-hPa-thick layer and they are opaque. The method parameterizes DLF as

$$
\mathrm{DLF}=\mathrm{DLF}_{\text {it }}\left(1-A_{1}\right)+\mathrm{DLF}_{\mathrm{iluy}} A_{1},
$$

where DLF il $_{\text {is }}$ the downward longwave flux for clear sky, DL.F $F_{\text {cls }}$ is the downward flux for cloudy sky, and $A$, is the cloud fraction. for which we use $A_{\text {s. }}$ from PathP. This equation is then simplified as

$$
\text { DIFF }=C_{1}+C_{2} A_{1} .
$$

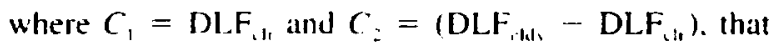
is, the thermal emission from the cloud base. The $C_{1}$ is parameterized in terms of the effective emitting temperature $T$, of the atmosphere (estimated from the surface and lower tropospheric temperatures) and the surface-to-70()-hPa water vapor burden $W_{1}(\mathrm{~mm})$ :

$$
C_{1}=f\left(W_{1}\right) T_{:}
$$

where $x$ is empirically determined to be 3.7. Further. $f\left(W_{1}\right)$ is expressed as

$$
f\left(W_{1}\right)=C_{1} / T_{:}=A_{0}+A_{1} V+A_{2} V^{2}+A_{3} V^{\prime} .
$$

where $V=\ln \left(W_{1}\right)$ and the $A$ s are regression coefticients. Equation (4) is then fit to fluxes and meteorological profiles from five sites in the United States to obtain the regression codficients $A_{0}=1.79 \times 10 ? A_{1}=$ $2.093 \times 10 \div . A_{2}=-2.748 \times 10 ?$. and $A_{3}=1.184$ $\times 10 "$.

The parameterization of $C_{2}$ contains the terms $T_{\text {ib }}$ (cloud-hase temperature) and $W$. (water vapor below the

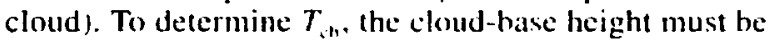
calculated from the satellite-retrieved cloud-top height. assuming a cloud thickness of $50 \mathrm{hPa}$ and a positive atmospheric lapse rate. Radiosonde data and a forward radiative transfer model are used to determine the relationship between $C_{:}$and $T_{. b}$ : 


$$
C_{2}=\frac{T_{i 1}^{1}}{\left(B_{1}+B_{1} W_{1}+B_{2} W_{i}^{2}-B_{3} W_{1}\right)}
$$

Tests by Gupta et al. (1992) using products from the International Satellite Cloud Climalology Project (ISCCP) dataset show that $(5)$ works well except when $P_{、}-P_{\text {sh }} \leq 200 \mathrm{hPa}\left(P_{\text {s }}\right.$ is the surface pressure, and $P_{\text {in }}$ is the pressure of the cloud base), which is a significant problem in the Arctic where low, thin clouds predominate.

\section{b. Fromin et al, $(1988)$}

This algorithm comprises two techniques (hereinafter $\mathrm{Fl}$ and $\mathrm{F2}$ ) for determining DLF during nighttime. The FI method requires temperature profiles, water vapor protiles, and cloud properties (cloud-top height and cloud traction), which we obtain from the Path-P dataset (Frouin et al. (1988) used operationa) NOAA TOVS retrievals\}. In this algorithm. clouds are assumed to exist in one opaque layer that is $50 \mathrm{hPa}$ thick. The temperature and water vapor profiles (from Path-P) are input to Strcamer to compute the clear-sky DLF. To estimate the cloudy-sky flux, we use the Path-P cloud effective fraction and cloud-top height and assign a cloud-base height that is $50 \mathrm{hPa}$ lower than the cloud-top height. Using the Path-P temperature profile. the cloud-base height is matched with the level of the corresponding temperature level to obtain the cloud-base temperature. This information is input to Streamer to calculate the cloudy-sky DLF. The clear-sky and cloudy-sky fiuxes are combined according to (1).

In F2, DLF is paramelerised as a function of the clearsky flux DLF c:s:

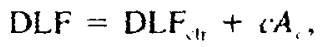

which is calculated as for F1. Again, we use $A_{1,}$ in place of cloud fraction. The coefficient c depends on latitude. season, and cloud type, which is determined by Frouin et al. (1988) by simulating DLF in varying cloud conditions using the Stephens (1978) model. A value of 66 $W \mathrm{~m}$ = is selected for this sludy. which corresponds (1) subarctic winter conditions and liquid water clouds.

Polar clouds rarely exist as a single layer (e.g. Schweiger and Key 1992): thus, we investigate the effects of multilayering by applying a cloud-overlap technique to the FI method using TOVS Path-P data as input. This random-bverlap technique is adopted from Tian and Curry (1989) and is being tested at the NASA Langley Research Center for the WCRP-GEWEX SRB program.

The overlap method comprises the following steps: 1) obtain cloud-top height and $A_{\text {ci. }}$ for each satellite retrieval in a $2.5^{\circ} \times 2.5^{\circ}$ region; 2) categorize the cloud type for each retrieval based on the ISCCP cloud-height definitions (high: top pressure below $440 \mathrm{hPa}$. middle: between 440 and $680 \mathrm{hPa}$, and low: greater than 680 $\mathrm{hPa})$. 3) determine the fraction of each cloud type in a region $\left(F_{11}, F_{M}\right.$, and $F_{1}$ for high. middle, and low $)$ 4) compute the probabilities $\left(C_{\text {M.r. }}\right)$ for each cloud type using the following equations:

$$
\begin{aligned}
& C_{H}=F_{H} / 1 . \\
& C_{M}=\left\{F_{M} l\left(1-F_{H}\right)\right\}, \text { and } \\
& C_{l}=F_{1} /\left(1-F_{H}-F_{M}\right)
\end{aligned}
$$

5) calculate clear-sky probabilities (e.g.. $1-C_{11}$ for high clouds); 6) calculate fractional values for combinations of conditions (clear, high alone, high over middle, high over low, high over middle over low. etc.); 7) calculate fluxes for each case (DLF, with appropriate cloud-base height (50-hPa thickness assumption) and $A_{\mathrm{cc}}$ using Streamer; and 8) multiply fluxes for each case by their corresponding fractional values $C_{i}$ :

$\mathrm{DLF}_{\mathrm{u}, \mathrm{j}}=\mathrm{DLF}_{1} C_{3}+\mathrm{DLF}_{2} C_{2}+\cdots+\mathrm{DLF}_{\mathrm{s}} C_{x}$.

where DLF $_{\text {wip }}$ is the new flux value from the cloudoverlap method.

\section{c. Francis (1997)}

The only assumptions in this method are that clouds exist in one layer and that cloud fraction is always $100 \%$, with all the variability in $A_{\text {ec }}$ occurring in the emissivily. Clouds may be optically thin and may have varying geometric thicknesses. This technique ingests $P$ ath- $P$ atmospheric temperature and moisture protiles, effective cloud fraction. cloud-top height, and surface temperature. Differences between brightness temperatures (TB) in several pairs of HIRS channels are used to estimate cloud type (positive or negative internal lapse rate). phase, thickness, and LWC of Arctic clouds. Cloud phase is inferred by suhtracting TBs in two pairs of channels: HIRS $10(8.3 \mu \mathrm{m})$ and HIRS $8(11.1 \mu \mathrm{m})$. and HIRS $18(4.0 \mu \mathrm{m})$ and HIRS $19(3.7 \mu \mathrm{m})$. For example, in the first pair, the absorption coefficients $k_{\text {an }}$ for water and ice are different. At $8.3 \mu \mathrm{m}, k_{\text {ath }}$ is similar for water and ice, but at $11.1 \mu \mathrm{m}$ the difference in $k_{\text {ith }}$ is large, thereby differentiating ice and water clouds.

Cloud thickness is estimated using TB differences in two pairs of channels: HIRS $6(13.7 \mu \mathrm{m})$ - HIRS 15 (4.46 $\mu \mathrm{m})$, and HIRS $14(4.52 \mu \mathrm{m})$ - HIRS 7 (13.7 $\mu \mathrm{m}$ ). The first pair is for mid- and high clouds (lop height $>750 \mathrm{hPa}$ ), and the second pair is used for low clouds. Because the weighting function peak of HIRS 6 is at a lower altitude than that of HIRS 15, its TB is warmer in a cloud-free sky. When a thin cloud is present. the difference in TB decreases. To determine the cloud thickness from the differences in TB, the base fraction, a value between 0 and 1 , is determined by setting endpoint thresholds and interpolating linearly between them by matching calculated DLFs to ohserved quantities.

The liquid or ice water content (IWC) is estimated using empirical relationships between mean cloud temperature and LWC or IWC for water or ice clouds. All 
this information is input to Stre imer to compute DLF. See Francis (1997) for further ditails of this algorithm.

The following three algorithiss are simple. empirically derived parameterizations. For this study the Path$P$ effective cloud fraction is used in place of cloud fraction in the relationships.

\section{d. Marshunova (J966)}

This method is an empirical y derived parameterization to estimate DLF based on surface temperature. near-surface vapor pressure, and cloud fraction. A simple cloud factor is defined that ixcludes the cloud fraction and a coefficient:

$$
D L F=D I F_{(1}\left(1+x A_{1}\right) .
$$

where

$$
\operatorname{DLF}_{\text {clt }}=r T t\left(0.67+0.05 e^{n s}\right)
$$

$x$ is a coefficient derived using time-varying surface temperatures $T_{.}$, and $e$ is near-s urface vapor pressure. In this study $x=0.26$ after an anilysis by Jacohs ( 1978 ). Effective cloud fractions and sk in temperatures are obtained from Path-P data. and $c^{\prime} \mathrm{i}$; calculated from Path$P$ moisture profiles.

\section{e. Zillman (1972)}

This parameterization is a function of both the cloud amount and the near-surface air temperature. The Path$P$ surface skin temperatures are used in this study, because our analysis of CEAREX measurements reveals that the surface skin temperalure rarely differs from the 2-m air temperalure by more th all $2 \mathrm{~K}$ except in prolonged clear winter conditions.

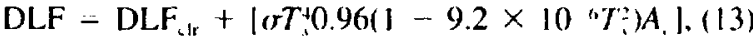

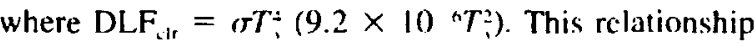
was derived hy Zillman (1972) fiom measurements over Antarctic sea ice obtained from Pease (1975).

\section{f. Morkut and Church (197.3)}

The relationship was developed with year-round surface temperature and cloud fration data collected in Barrow. Alaska, over a 5-yr period. during which the surface temperature ranged from 244 to $277 \mathrm{~K}$. The DLF is parameterized as

$$
\text { DLF }=\text { DLF }_{\text {, }}\left(1+0.22 A_{1}^{275}\right) .
$$

where $\mathrm{DLF}_{\mathrm{cl}}=0.7855 \mathrm{r} T^{4}$.

\section{Results and discussion}

\section{a. Performance of DLF algmitums}

Downward longwave fluxes at the surface are computed using each of the cight mothods described in sec- tion 4 and listed in Table 2. Fluxes calculated from dailyaverage input data are compared to daily-average measured fluxes from the CEAREX and LeadEx field programs. Scatterplots that illustrate direct comparisons of the computed and measured fluxes are shown in Fig. 5 . and a summary of the comparison stalistics is presented in Table 3.

The rms differences and correlation coefficients are remarkably similar for all eight methods: hence. they are listed in decreasing accuracy according to bias. All the methods exhihit negative bias, that is. calculated fluxes are too small. although it is negligible for the Francis (1997) algorithm. which is one of the four specifically designed for polar conditions. The cloud-overlap method applied fo F1 clearly improves the results: the bias is reduced from $-34(16 \%)$ to $-11(5 \%)$ w $\mathrm{m}$ :. Results from the other three Arctic-specific methods /Marshunova (1966): Maykut and Church (1973); Zillman (1972)], although only simple parameterizations, are disappointing. These same three parameterifations were evaluated by Key et al. (1996) using validation data from two land stations: Resolute. Northwest Territorics, Canada, and Barrow. Alaska. When compared with Key et al. (1996), the Maykut and Church (1973) algorithm exhibited a bias one-half as large as in our study. probably because it was developed with data from Barrow. Alaska. The Zillman (1972) parameterization. developed with data from the Southern Ocean was. not surprisingly. the least accurate of the three in both cvaluations. Our results yielded a larger negative bias for the Marshunova (1966) method, again probably because the parameterization was developed using data from Arctic coastal stations such as Resolute and Barrow rather than observations from within the Arctic Ocean.

\section{b. Sources of error}

\section{1) ATMOSPIFRIC PROFILES}

The reported bias in Path-P temperature profiles is approximately I $\mathrm{K}$ (Schweiger el al. 2001), which translates to an error in DLF of about $3 \mathrm{~W} \mathrm{~m}:$ in summer and $1.5 \mathrm{~W} \mathrm{~m}$ " in winter. The bias in water vapor protiles, as compared with radiosonde dala from the SHEBA tield program. is about $10 \%$, which would produce an error in DLF of approximately $3 \mathrm{~W} \mathrm{~m}=$. We consequently conclude that errors in saltellite-retrieved tcmperature and water vapor profiles do not contribute significantly to the apparent biases in computed DLF.

\section{2) Cloud hRACTION}

Because all of these algorithms require information about cloud fraction and because DLF in polar regions is sensitive to cloud fraction, this variable may account for much of the error in computed DLF. As already mentioned. the Path-P product used in the analyses is 

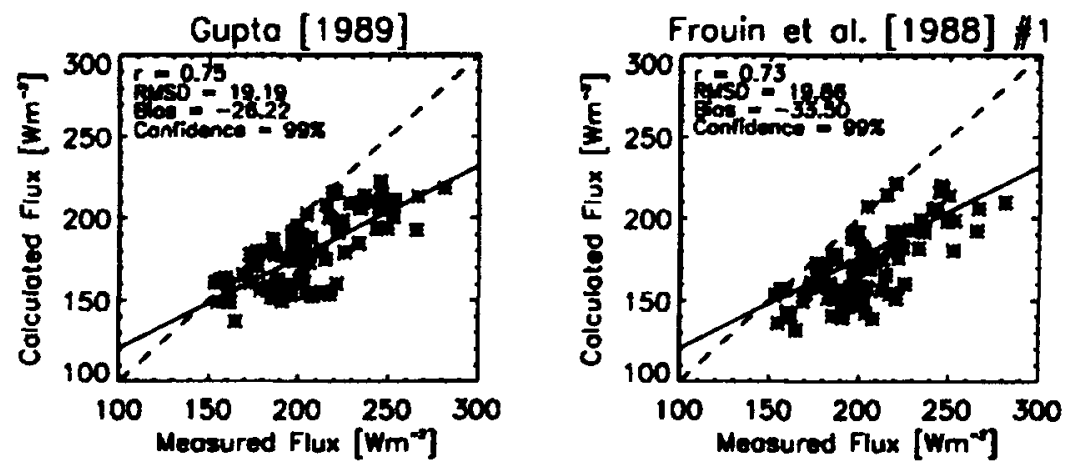

Frouin el ol. [1988] $11 \mathrm{w} / \mathrm{OL}$

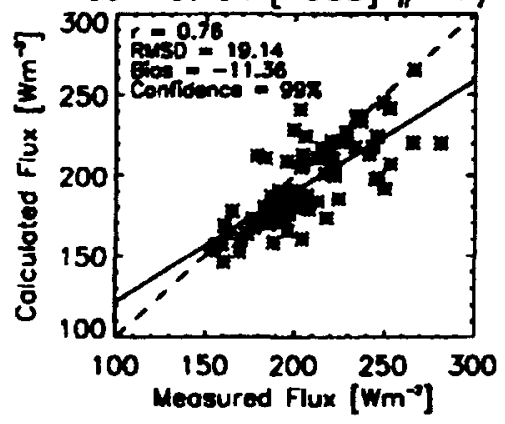

Frouin et ol. [1988] 2
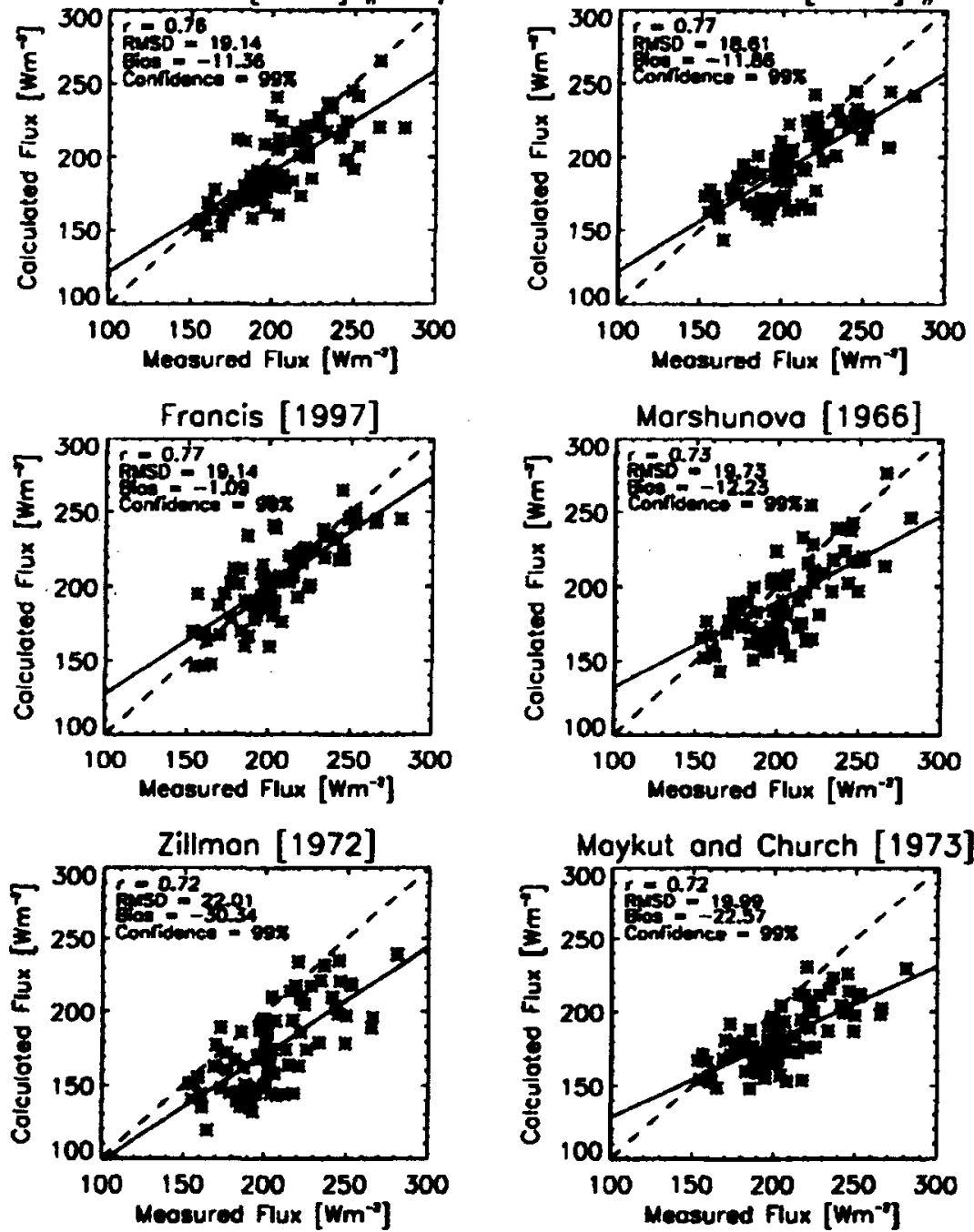

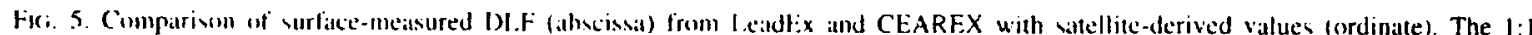
(dashed) and least squares-fit (solid) lines are shown. RMSD is the root-mean-square dilference. Regression line slopes are different from I with a contidence >yy\%. 
Tab1.l: 3. Ranked comparson stativic af algorithen performance.

\begin{tabular}{|c|c|c|c|}
\hline Algorithm reference & $\begin{array}{l}\text { lian (W m ) R } \\
\text { / of mein) }(\mathrm{W}\end{array}$ & $\begin{array}{l}\text { Rmse } \\
\text { A m ' I }\end{array}$ & $r^{*}$ \\
\hline Francis (1997) & $-1(0.1)$ & 19 & 0.77 \\
\hline Frouin et al. (1988). FI with overlap & $11(5)$ & 19 & 0.76 \\
\hline Frouin at al. (1988). F2 & $.12(6)$ & 19 & $1) .77$ \\
\hline Marshumova (19661 & $-13(6)$ & 20 & 0.73 \\
\hline Maykut and Church (1973) & $-23(11)$ & 20 & 0.72 \\
\hline Gupta (1989) & -261121 & 19 & 0.75 \\
\hline Zillman (1972) & $-3(1)(1+1$ & 22 & 1). 72 \\
\hline Frouin et al. (1988). F) & $\cdots 34(16)$ & 20 & 0.73 \\
\hline
\end{tabular}

* Here $r$ is correlation cuefficiem.

the effective cloud traction, which is the product of the cloud emissivity and the cloud fraction. Four of the algorithms we evaluate assume that clouds are black (i.e., opaque) and $50 \mathrm{hPa}$ thick. These separate assumptions will contribute to er ors of different signs. Clouds with emissivities less tha 1 unity (nonblack) have been observed in the Arctic ( Curry et al. 1996). In these cases, which theoretically would yield a retrieved $A_{\text {w. }}$ that is smaller than the surface-cbserved cloud fraction, the opaque assumption will canse an overestimate in DLF because a black cloud will emit more infrared radiation. all other characteristic: heing equal. The assumption of a 50-hPa-thick cloud, on the other hand. will cause an underestimation o: DLF if the cloud base is actually lower.

To produce a DLF that is hiased by $-30 \mathrm{~W} \mathrm{~m}$ ?, the cloud fraction would have to be 100 small by approximately $60 \%$ for low clouds an 1 even larger for high clouds, according to our sensitivity tests. A comparison of cloud climatological descriptions from nine different sources / seven based on human ibservers and two from satellites (Chiacchio 2001)) show's that mean Path-P values for April (48\%) fall in the middle of the range of values (29\% (Vowinckel and Orı ig 1970) to 89\% (Barry et al. 1987)|. Excluding (including) the single large outlier. the mean is $46 \%(51 \%)$ anc the standard deviation is $8.5 \%(16.5 \%)$.

In addition, we compare cellometer-derived cloud fractions from the LeadEx field program to those from Path-P (Fig. 6). Although the day-to-day variability is lower in Path-P retrievals, they appear to be slightly larger than the ceilometer valuis. As previously mentioned, however, the ceilometer sften did not sense thin low clouds, which probably con! ribute's to the large discrepancies near year days 89, 199, and 106-109 when the ceilometer retrievals wert cl ar (Fig. $6 c$ ). Data from the SHEBA field project analyied by Schweiger et al. (2001) did not exhibit this behavior. however; lidarderived cloud fractions were sy itematically larger than those reported by human observers. Based on these results, we conclude that errors in Path-P $A_{c a}$ retrievals are not responsible for the large negative biases exhibited by most of the DLF algorihms.

\section{3) Cl.OLID-B.ASI: HEIGHT}

Cloud-base height in three of the algorithms is determined by assuming it is $50 \mathrm{hPa}$ lower than the PathP-retrieved cloud-top height. Thus there are 1 wo components of this variable to consider: First is the accuracy of cloud-top height in the Path-P dataset and how it differs from heights estimated using lidar ceilometers. The cloud top can be difficult to define. because cloud boundaries are often ephemeral and partially transparent to infrared radiation. A comparison of surface-based. lidar-radar-retricved cloud-top heights with those from Path-P during SHEBA. for example. shows that cloud tops are generally higher in lidar-radar retrievals than those from Path-P (Schweiger et al. 2001). This behavior is expected because of inherent differences in the two observing techniques: the lidar-radar system is sensitive to the small, sparse ice particles that frequently compose high-latitude cloud tops. whereas $P$ ath-P retrieves a value corresponding to the effective radiating height. that is the height from which the hulk of the radiation is emitted from the cloud top. Although no conclusion can be drawn at this time regarding the veracity of Path-P cloud-1op height retrievals. we do know that to contribute to negative biases in computed DLF. the retrieved cloud tops would have to be consistently too high, which is not what Schweiger et al. 12001$)$ show.

The second issue is the assumption of a constant. 50hPa cloud thickness. as in Gupta (1989). Fl. FI with overlap. and F2. We compare ceilometer-observed cloud-base heights from LeadEx to those estimated using the Path-P retrieved cloud-top heights assuming a 50-hPa thickness (Fig. 6a). Cloud-base height ohserved by the ceilometer is markedly lower than that obtained assuming a 50-hPa thickness (bias $=1200 \mathrm{~m}$ ), which can be explained either by retrieved cloud tops that are too high or thicknesses that are too thin. Whichever the cause, this positive bias results in surface fluxes heing much lower than observed and is the most likely source of error in the calculated DLFs. Furthermore. if Path-P cloud-top heights are generally lower than the actual values, as suggested by the SHEBA comparison, the 50 hPa assumption may be even less realistic than these results indicate. Including the cloud-overlap technique in FI makes a considerable improvement (Fig. (6b) by representing multiple cloud layers and effectively lowering the cloud base.

Our sensitivity calculations show that if a low-cloud base were $50 \mathrm{hPa}$ (about $500 \mathrm{~m}$ ) 100 high. the DLF would be about $20 \mathrm{~W} \mathrm{~m}$ : too small with a typical winter Arctic temperature protile. The algorithms that assume a 50 -hPa-thick cloud exhibit an average bias of approximately this amount. We therefore conclude, based on these results. that the 5()$-\mathrm{hPa}$ cloud thickness assumption is unsuitable for Arctic winter conditions and that a more realistic value would be approximatcly 2 limes as thick. 

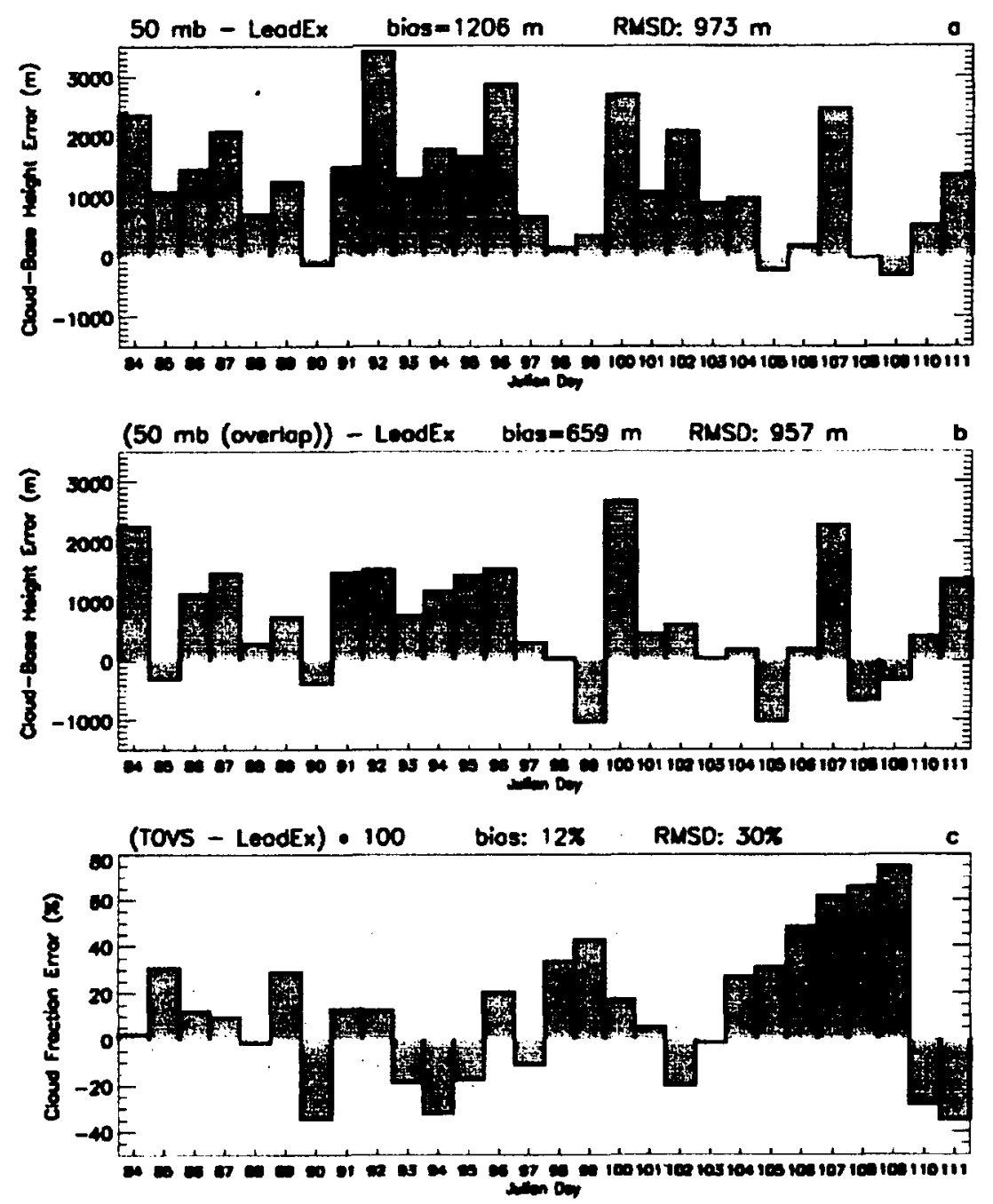

Fili. 6. Differences belween ubserved and retrieved cloud-base height cstimated using Path-P cloud-top height and assuming (a) a 50 -hPa thickness; (b) cloud-base height as in (a), but with random-cloud-overlap method applied: and (c) difference in cloud fraction. Observed cloud-hase heights and fractions are from the LeadEx ceilometer; retrievals are from Path-P.

\section{4) OTHER SOURCT:S OF ERROR}

The poor results exhibited by the Marshunova (1966). Zillman (1972), and Maykut and Church (1973) parameterizations are somewhat surprising, given that they were developed for polar conditions. Because they are so simple, it is difficult to ascertain the cause of the errors, but it is likely that they arise because the parameterizations were developed using human-observed cloud fractions rather than values derived from remote sensing instruments.

Apparent errors in all methods may arise because of the inherent differences in comparing daily averaged, point-flux measurements with values computed from $(100 \mathrm{~km})^{2}$ retrieved atmospheric parameters. In addition. a negative (clear sky) bias may be introduced because TOVS retrieval boxes with greater than $90 \%$ ef- fective cloud fraction are rejected (Francis 1997). Errors may also result from differences in perspectives by surface observers and satellites for both cloud height and cloud fraction. A surface observer has a bottom-up view, whereas satellites look down on the cloud top. Surface observations of cloud fraction are usually larger than those derived from satellites owing to differences in view angles and the sky field of view (Schweiger and Key 1992; Chiacchio 2001).

\section{Summary and conclusions}

The dominant component of the Arctic surface energy budget during almost one-half of the year is longwave radiation; however, its spatial and temporal scales of variability are not known well, and a reliable, basinwide 
dataset is not available. A long-term dataser of surface radiation is needed for a variety of applications in climate research. A number of methols with varying degrees of complexity exist for estmating DLF from satellite and surface measurements and, although surface parameterization schemes were intercompared and evaluated throughly by Key et al. (1996), there is little information about the performince of satellite-based techniques in polar nighume conditions. In this study we attempt to evaluate several of these methuds and to identify reasons for their apparent shoricomings.

In dry polar conditions, cloud properties primarily govern DLF In particular, our semsitivity tests show that DLF is most sensitive to uncortanties in cloud fraction. LWC and thickness while boing insensitive to droplet radius. All of the techniques $w$ : tested require an estimate of cloud fraction as inpul. some requite temperature and moisture information, and one ingests satellite brightness temperatures lirectly. Four of the methods atsume that clouds are a constant $50-\mathrm{hPa}$ thick, three contain no thickness information whatsoever, and all algorithms but one assume clonds exist in one layer. Only one algorithm allows for varying cloud thickness and emissivity. Using satellite-derived Path-P products as input for the eight DLF mellonds, we found that all techniquer except one exhibit , large $\{>10 \mathrm{~W} \mathrm{~m}$; negative bias as compared with measurements from two field programs in the Arctic win er and spring. The rms errors and correlation coefficien ts do not vary significantly anong the methods. however, suggesting that cloud fraction. the same data for which are ingested by all methods. probably accounts for much of the variability. Our efforts, consequently, focused on identify. ing the cause(s) of the consistent negative biases.

Errors in atmospheric tempelature and water vapor protiles from the Path-P dataset were eliminated as probable sources of deficient DLFs, xcausc reported biases in the Path-P profiles could atce unt for only about $4 \mathrm{~W}$ $m^{2}(2 \%$ of mean DLF). Path-P 8 fiective cloud fractions were also dismissed as a likely source, bewause comparisons with surface observations (both by humans and active remote sensing instruments) reveal a small positive bias in cloud fraction. which would result in a poxitive bias in DLF. Several of the methods require a cloud-top height extimate. for which we used the Path$P$ product. This is a difficult varmatele to verify owing to inherent differences among observing methous, but it is likely that Path-P cloud-top lieights are biasted somewhat negatively, which would again result in cloud bases that were too warm and DI Fs that were wo large. Thus errors in cloud-top height retrievals probably do not account for the negatively biased calculated DLF values. The most likely source of error. therefore. is the assumption by one-hall of the algorithmes that clouds are $50 \mathrm{hPa}$ thick. Model cakulat ons show that if a cloud layer were $50 \mathrm{hPa}$ too thin. the DLF would be approxinvately $20 \mathrm{~W} \mathrm{~m}$ : 100 small. Having eliminated the other likely sources of error. $w$ : conclude that the 50 .
hPa-thickness assumption shoukd not he applied during polar winter conditions and that, if a constant could thickness is required, a value approximately 2 times as large should be used. This conclusion is further supported by the results of applying a random-cloud-overlap method, which effectively lowers the mean cloud base, and by the lack of a DLF bias in the one method that ingests the cloud-trop height but atlempts to estimate cloud-hase heights from differences in satellite-observed brightness temperatures.

Our detaled conclusions are presented below.

1) All eight methods exhibited varying degrees of negative bias, ranging from $-1(0.5 \%) 10-34 \mathrm{~W} \mathrm{~m}=$ (16\%) as compared with surface measurements of DLF; rms errors and correlation coeficients did not vary significantly.

2) The assumption of a constant. $50 \mathrm{hPa}$ cloud thickness is the most likely cause of negative DLF biases. Based on our analysis, we suggest that if a constant cloud thickness is used for Arctic winter conditions, it should be doubled to $100 \mathrm{hPa}$. We note, however, that the sample size for this analysis is no large 78 total collocations from CEAREX and LeadEx) and validation data cover only one aulumn-winter season in the region northeast of Spitsbergen and one spring season in the Beaufort Sea.

3) Application of a technique to simulate random cloud overlapping reduces the bias by the FI method from -34 in $-11 \mathrm{~W} \mathrm{~m}$ ?. This improvement is believed to be the result of effectively lowering the mean cloud base.

4) The most accurate DLF algorithm may be Francis 1997), which exhibits a bias of $-1 \mathrm{~W} m$ : when compared with surface measurements. This method is specifically developed for Arctic conditions. atlows for clouds within inversion layers, differentiates ice and water clouds, and does $n$ ascume cloud thickness to be constant. We recommend its use for Arctic autumn, winter, and spring conditions. Its performance in the summer has not been evaluated yet.

5) The $F_{2}$ method outperforms the $F 1$ algorithm because the crefficient in the formulation depends on location. season. and cloud type.

6) Simple parameterizations designed specifically for polar sonditions (Maykut and Church (1973); Zill. man (1972): Marshunova (1966)] did not perform well, probably because they were formulated using surface-observed cloud fractions from land stations. whereas we used satellite-retrieved effective cloud fractions.

7) Errors in satellite-retrieved temperature and water vapur profiles do not contribute significanty to the negative biases exhihited by calculated DLFs.

8) Comparisons of Path-P effective cloud fraction with ceilometer-retrieved values indicate a slight positive bias, which would contribute to a positive bias in DLF. We therefore rule out erross in cloud fraction 
as the source of consistent negative biases in calculated DLFs.

9) Attempts to validate Path-P cloud-top heights suggest they may be too low, which would also contribute to a positive DLF bias. We therefore dismiss this variable as a source of negative DLF biases.

10) DLF in the winter Arctic is most sensitive to cloud fraction, LWC, and cloud thickness; cloud droplet size has a negligible effect on DLF.

In summary, we have presented quantitative analyses of the sensitivity of downwelling longwave fluxes to realistic uncertainties in satellite-derived atmospheric parameters in typical Arctic winter conditions. The most complex of the algorithms we tested, which includes a technique to estimate cloud-base height and emissivity. produces DLFs that are closest to measured fluxes in these conditions. We found that simpler algorithms that assume clouds have a constant thickness and have unit emissivity perform poorly in the Arctic, but biases in their results are significantly improved by doubling the assumed cloud thickness. This analysis should be extended to include all seasons, perhaps using measurements from the SHEBA experiment and more locations representative of polar conditions.

Acknowledgments. We thank the reviewers, particularly J. Key, for their careful reading of the manuscript and helpful comments. We are also grateful to Dr. Shashi Gupta for valuable discussions regarding his radiative transfer model and for general comments. Funding for this project was provided by NASA Grants NAG-11908 and NAG- 1 -2058 (CERES).

\section{REFERENCES}

Barry, R. G.. R. G. Crane. A. Schweiger, and J. Newell, 1987: Arctic cloudiness in spring from satellite imagery. J. Climatol. 7, 423451 .

CEAREX Drift Group, 1990: CEAREX Drift Experiment. Eos, Trans. Amer. Ceophys. Union. 71, 1115-1118.

Chédin. A., N. A. Scott. C. Wahiche. and P. Moulinier, 1985: The Improved Initialization Inversion Method: A high-resolution physical method for temperature retrievals from satellites of the TIROS-N series. J. Climale Appl. Meterr., 24, $128-143$.

Chiacchio. M.. 2001: The evaluation and improvement of downward longwave flux algorithms in the polar night for the Clouds and the Earth's Radiant Energy System (CERES) Program. M.S. thesis. Dept. of Environmental Science. Rutgers University, $86 \mathrm{pp}$.

Curry, J. A.. and E. E. Ebert, 1992: Annual cycle of radiation fluxes over the Arctic Ocean: Sensitivity to cloud optical properties. J. Climare, 5, 1267-1280.

-W. B. Rossow, D. Randall, and J. L. Schramm. 1996: Overview of Arctic cloud and radiation characteristics. J. Climate. 9, 17311764.

Ellingson, R. G., J. Ellis, and S. Fels, 199J: The intercomparison of radiation colles used in climate models: Longwave results. $J$. Geophys. Res., 96, 8929-8953.

Francis, J. A., 1994: Improvements to TOVS retrievals over sea ice and applications to estimating Arctic energy fluxes. J. Geophys. Re's., 99, $10395-10408$.
- 1997: A method to derive downwelling longwave fuxes at the Arctic surface from TOVS data. J. Gerphys. Kes., 102, 17951806.

- 1999: Cloud radiative forcing over Artic surlaces. Preprints. Fiffh Conf. on Polar Meteorology and Occanographs. Dallas. TX. Amer. Meteor. Suc., 221-226.

- and A. J. Schweiger, 2000: A new window opens on the Arctic. Eos, Trans. Amer. Geophys. Union, 81, 77-83.

Frouin, R., C. Gautier, and J.-J. Morctette, 1988: Downward longwave irradiance at the ocean surface from salellite data: Methodology and in situ validation. J. Geophis. Res., 93, 507-619.

Gupta. S. K.. 1989: A parameterization for longwave surtace radiation from sun-synchronous satellite data. $J$. Climate, 2, 305-320.

-.-. W. L. Darnell, and A. C. Wilber, 1992: A parameterization for longwave surface radiation from satellite data: Recent improve ments. J. Appl. Meteor., 31, 1361-1367.

- N. A. Ritchey, A. C. Wilber. and C. H. Whitlock, 1999: A climatology of surface radiation budget derived from satellite data. J. Climate, 12, 2691-2710.

Intricri, J. M.. M. D. Shupe, T. Uttal. and B. J. McCarty, 2001: An annual cycle of Arctic cloud characteristics observed by ritdar and lidar at SHEBA. J. Geophys. Res., in press.

Jacobs, J. D., 1978: Radiation climate of Broughton Island. Energy Budget Studies in Relation on Fast-lie Breakup Processtes in Davis Strair. R. G. Barry and J. D. Jacobs, Eds.. Paper 26. INSTARR. University of Colorado, 105-120.

Key. J., and A. J. Schweiger. 1998: Tools for atmospheric radiative transfer: Streamer and FluxNet. Comput. Geosci. 24, 443-451.

- , R. S. Silcox, and R. S. Stone, 1996: Evaluation of surface radiative flux parameterizations for use in sea ice models. $J$. Geophys. Res., 101, 3839-3849.

-_. A 1. Schweiger, and R. S. Stone, 1997: Expected uncertainty in satellite-derived estimates of the high-latitude surface radialion budget. J. Geophys. Res., 102, 15 837-15847.

LeadEx Group, 1993: The Lead Experiment. Eos, Trans. Amer. Geophys. Uniom, 393-397.

Marshunova. M. S. 1966: Principal characteristics of the risdiation. balance of the underlying surface. Soviet data on the Arctic heat budget and its climate influence, Rep. R. M. 5(N)3-PR, Rand Corp.. Santa Monica. CA. 205 pp.

Maykut, G. A., and P. E. Church, 1973: Radiation climate of Barrow. Alaska, 1962-1966. J. Appl. Meteor. 12,620-628.

Pease, C. H.. 1975: A model for the seasonal ablation and accretion of Antarctic sea ice. AIDJEX Bull., 29, 151-172.

Raschke, E.. H. Cattle. P. Lemke, and W. Rossow. Eds., 1940: WCRP report on polar radiation fluxes and sea-ice modeling. World Climatt Research Progranme. Bremerhaven. Germany, $140 \mathrm{pp}$.

Schmet\%, P., J. Schmetr. and E. Raschke. 1986: Estimation of ditytime Jownward longwave radiation at the surface from satellite and grid point data. Theor. Appl. Climatol. 37, 136-149.

Schweiger. A. J., and J. R. Key, 1992: Arctic cloudiness: Comparisons of ISCCP-C2 and Nimbus-7 satellite-derived claud properties with at surface-based cloud climatology. I. Climate. 5, 15141527.

- R. Lindsay. J. A. Francis, J. Key. J. InIrieri, and M. Shupe. 2001: Validation of TOVS Path-P data during SHEBA. J. Geophys. Res.. in press.

Seott. N. A., and Coathors, 1999: Characteristics of the TOVS pathfinder Path-B dataset. Bull. Amer. Meteor. Soc., 80, 2679-2701.

Stephens, G. L., 1978: Radiation profiles in extended water clouds. 1. Theory. J. Atmes. Sci.. 35, $2111-2122$.

Tian, L.. and J. A. Curry, 1989: Cloud overlap statistics. J. Gerophys. Res., 94, 9925-9935.

Vowinckel. E.. and S. Orvig, 1970: The climate of the North Polar hasin. Climate of the Palar Regions. S. Orvig. Ed., Elsevier, $129-239$.

Zillman. J. W., 1972: A study of some aspects of the ratiation and heat budgets of the Southern Hemisphere oceans. Bureau of Meteurology Rep. 26. [Available from Bureau of Meteorology. Dept. of the Interior. Canberra, ACT 2601. Australia.] 